\title{
Optimal cut-offs of four anthropometric measures and their predictive ability of diabetes in a nationally representative Kenyan study
}

Anthony Muchai Manyara ( $\sim$ muchai.manyara@gmail.com )

University of Glasgow https://orcid.org/0000-0001-6276-926X

\section{Research Article}

Keywords: Diabetes, prediction, anthropometric cut-offs, Kenya, Africa, waist circumference, waist-toheight ratio

Posted Date: March 11th, 2021

DOI: https://doi.org/10.21203/rs.3.rs-317550/v1

License: (c) (i) This work is licensed under a Creative Commons Attribution 4.0 International License. Read Full License

Version of Record: A version of this preprint was published at AIMS Public Health on July 9th, 2021. See the published version at https://doi.org/10.3934/publichealth.2021041. 


\section{Optimal cut-offs of four anthropometric measures and their predictive ability of diabetes in a nationally representative Kenyan study}

\section{Anthony Muchai Manyara ${ }^{1}$}

1 School of Social and Political Sciences, Institute of Health and Wellbeing, University of Glasgow, Glasgow, UK.

*Corresponding author

Anthony Muchai Manyara

Email: Muchai.manyara@gmail.com 


\section{Abstract}

Background

Type 2 diabetes (T2D) is one of the top non-communicable diseases in Kenya and prevention strategies are needed. Intervening to reduce obesity is the most common prevention strategy. However, black ethnicities develop T2D at lower obesity levels and it is unclear what anthropometric cut-offs could provide the best predictive ability for T2D risk. This study, therefore, aimed to determine the optimal anthropometric cut-offs and their predictive ability of T2D.

Methods

The study included 2159 participants (59\% women) aged 35-69 years from the Kenya STEPwise survey conducted in 2014. Four anthropometric measures - body mass index (BMI), waist circumference (WC), waist to hip ratio (WHR), and waist to height ratio (WHtR) - were used. Diabetes was defined as a fasting blood glucose of $\geq 7.0 \mathrm{mmol} / \mathrm{l}$ or a previous diagnosis for diabetes. Optimal anthropometric cut-offs and their receiver operating characteristics, such as the area under the curve (AUC), were computed.

Results

Overall, the optimal cut-off for BMI, WC, WHR and WHtR were $24.8 \mathrm{~kg} . \mathrm{m}^{-2}, 90.0 \mathrm{~cm}, 0.88$ and 0.54 . On disaggregation by sex, the optimal cut-off for BMI, WC, WHR and WHtR was $27.1 \mathrm{~kg} \cdot \mathrm{m}^{-2}, 87 \mathrm{~cm}, 0.85$ and 0.55 in women and $24.8 \mathrm{~kg} \cdot \mathrm{m}^{-2}, 91 \mathrm{~cm}, 0.88$, and 0.54 in men. Overall, WC (AUC 0.71 (95\% confidence interval $0.65,0.76)$ ) had a better predictive ability for T2D than BMI (AUC 0.68 $(0.62,0.73)$, $\mathrm{p}=0.0314)$ ). Also, WHtR (AUC $0.71(0.66,0.76))$ had better a predictive ability for T2D than BMI (AUC $0.68(0.62,0.73), p=0.0182))$.

Conclusions 
WC and WHtR were better predictors of T2D than BMI and should be used for risk stratification in Kenya. A WC cut-off of $87 \mathrm{~cm}$ in women and $91 \mathrm{~cm}$ in men, or a WHtR cut-off of 0.55 in both men and women should be used to identify individuals at high risk of T2D.

Keywords: Diabetes, prediction, anthropometric cut-offs, Kenya, Africa, waist circumference, waistto-height ratio

\section{Introduction}

The prevalence of diabetes is on the rise in sub-Saharan Africa (SSA) exerting a disease and economic burden (1). Type 2 diabetes (T2D), the main type of diabetes, is preventable through lifestyle modification such as weight loss (2). Excess body fat is an important risk factor for T2D and anthropometric measures that estimate body fat such as body mass index (BMI), waist circumference (WC), waist to hip ratio (WHR), and waist to height ratio (WHtR) have been used to predict risk (3). However, debate remains on which is the best measure to characterise risk. Despite BMI being the most used measure it has been challenged on its inability to: 1) differentiate between body lean mass and fat mass; and 2) detect the location of body fat (4). Central obesity measures (WC, WHR, WHtR) that are proxies of visceral fat may be better measures of risk as visceral fat is more important for T2D development than peripheral fat (5). Consequently, a meta-analysis of 20 studies reported that WHtR and WC provide a more robust measure for detecting T2D than BMI (6). In SSA, several studies have reported central obesity measures as better predictors of T2D than BMI (7-13). However, it remains unclear which measure has a better predictive ability. For instance in Ghana and Ethiopia, WHR was a better predictor of diabetes in three studies $(8,11,12)$ while WC was a better predictor of diabetes in five studies from Ethiopia, Cameroon, Kenya, and Guinea (7, 9-12).

Further, there is increasing evidence that black populations develop T2D at lower obesity levels compared to whites, and therefore current anthropometric cut-offs may be less appropriate for them. For example, the age-adjusted prevalence of T2D in whites at $30 \mathrm{~kg} \cdot \mathrm{m}^{-2}, \mathrm{WC}$ of $102 \mathrm{~cm}$ in men, and 
$88 \mathrm{~cm}$ in women equated to a BMl of $26 \mathrm{~kg} \cdot \mathrm{m}^{-2}, \mathrm{WC}$ of $88 \mathrm{~cm}$ and $79 \mathrm{~cm}$ in men and women respectively in the black ethnicity (14). There is emerging but limited evidence of the optimal cut-offs to predict T2D in SSA. In Ghana, the optimal cut-offs for BMI, WC and WHR were $26.2 \mathrm{~kg} \cdot \mathrm{m}^{-2}, 91.7 \mathrm{~cm}$ and 0.88 for women, and $26.7 \mathrm{~kg} \cdot \mathrm{m}^{-2}, 83.4 \mathrm{~cm}$ and 0.90 for men (8). Recently, an Ethiopian study reported that the optimal cut-offs for BMI, WC, WHR and WHtR were $20.5 \mathrm{~kg} . \mathrm{m}^{-2}, 82.9 \mathrm{~cm}, 0.86$ and 0.51 in women, and $23.0 \mathrm{~kg} \cdot \mathrm{m}^{-2}, 88.6 \mathrm{~cm}, 0.97$ and 0.52 in men (12). This study, therefore, aimed to determine the optimal anthropometric cut-offs of four measures (BMI, WC, WHR, WHtR) for predicting T2D in Kenya and compare their predictive ability.

\section{Methodology}

The study used data from the Kenya STEPwise survey 2014 which was a nationally representative study that investigated non-communicable diseases risk factors. A multi-stage cluster sampling method was used to recruit 4479 participants aged $18-69$ years. Data were collected by trained personnel and involved the administration of a questionnaire, physical and biological measurements (15). More information on the survey can be found elsewhere (15).

\section{Inclusion and exclusion criteria}

To limit analyses to type 2 diabetes cases we included participants between 35 and 70 years of age as type 2 diabetes prevalence increases with age (16) and type 1 diabetes is relatively low from $\geq 35$ years of age (17). A total of 2159 participants with complete data on all anthropometric measures and diabetes diagnosis were included in the analysis.

\section{Data collection procedures and definitions}

Height was measured in centimetres using a portable stadiometer and weight was measured in kilogram using a portable electronic weighing scale. Waist circumference was measured at the umbilicus level using a constant tension tape. Blood pressure was measured three times using an automated blood pressure measuring instrument $\left(\mathrm{OMRON}^{\circledR}\right)$. A minimally invasive prick was used to 
draw a blood sample and CardiocheckPA analyser ${ }^{\circledR}$ was used to measure blood glucose levels (15). Body mass index was calculated by dividing weight in kilograms by height in metres squared. It was categorised into: underweight $\left(<18.5 \mathrm{~kg} \cdot \mathrm{m}^{-2}\right)$, normal weight $\left(18.5-24.9 \mathrm{~kg} \cdot \mathrm{m}^{-2}\right)$, overweight $(25-29.9$ $\mathrm{kg} \cdot \mathrm{m}^{-2}$ ) and obese $\left(\geq 30 \mathrm{~kg} \cdot \mathrm{m}^{-2}\right)$ (18). Diabetes was defined as a fasting glucose of $\geq 7.0 \mathrm{mmol} / \mathrm{l}$ or a previous diagnosis by a health worker (19).

\section{Analysis}

All data analysis was done using R statistical package version 3.5.2 (20). Means and standard deviations were used to summarise continuous variables, and frequencies and percentages used to summarise categorical variables. The 'OptimalCutpoints' package was used to compute the optimal anthropometric cut-offs and their receiver operating characteristics (ROC) using the Youden Index. The characteristics computed were: the Area Under the Curve (AUC), sensitivity, specificity, positive predictive value, and negative predictive value associated with each cut-off (21). The 'pROC' package was used to compare the AUC of anthropometric measures using BMI as the reference (22). The ROC curves of all four anthropometric measures were plotted to show sensitivity ( $y$-axis) and specificity ( $x$ axis). Data are presented for the overall sample and by sex disaggregation. A statistical significance level of $p<0.05$ was used.

\section{Results}

Table 1 presents the characteristics of the 2159 study participants included in the analyses. The average age was 48 years, and the diabetes prevalence was $6.6 \%$ in women and $4.3 \%$ in men. The majority of both women and men were of normal weight status. 


\begin{tabular}{|c|c|c|c|}
\hline & $\begin{array}{c}\text { All } \\
n=2159\end{array}$ & $\begin{array}{l}\text { Women } \\
n=1271\end{array}$ & $\begin{array}{l}\text { Men } \\
n=888\end{array}$ \\
\hline Age - mean $\pm S D$ & $48.1 \pm 9.9$ & $48.4 \pm 10.0$ & $47.7 \pm 9.8$ \\
\hline Height $(\mathrm{cm})-$ mean \pm SD & $163.6 \pm 9.5$ & $159.2 \pm 7.8$ & $170.1 \pm 8.0$ \\
\hline Diabetes prevalence $-\mathrm{n}(\%)$ & $122(5.7)$ & $84(6.6)$ & $38(4.3)$ \\
\hline $\begin{array}{l}\text { Systolic blood pressure }(\mathrm{mmHg})-\text { mean } \pm \\
\text { SD }\end{array}$ & $134.0 \pm 23.5$ & $134.1 \pm 24.4$ & $133.8 \pm 22.2$ \\
\hline $\begin{array}{l}\text { Diastolic blood pressure }(\mathrm{mmHg}) \text { - mean } \\
\pm \mathrm{SD}\end{array}$ & $85.8 \pm 13.4$ & $86.6 \pm 13.7$ & $84.7 \pm 13.0$ \\
\hline $\mathrm{BMI}\left(\mathrm{kg} \cdot \mathrm{m}^{-2}\right)-$ mean $\pm \mathrm{SD}$ & $24.2 \pm 5.9$ & $25.2 \pm 6.2$ & $22.7 \pm 5.0$ \\
\hline Weight status - n (\%) & & & \\
\hline Underweight & $240(11.1)$ & $109(8.6)$ & $131(14.8)$ \\
\hline Normal & $1108(51.3)$ & $587(46.2)$ & $521(58.7)$ \\
\hline Overweight & $491(22.7)$ & $325(25.6)$ & $166(18.7)$ \\
\hline Obese & $320(14.8)$ & $250(19.7)$ & $70(7.9)$ \\
\hline Hip circumference $(\mathrm{cm})-$ mean $\pm S D$ & $95.8 \pm 14.6$ & $97.9 \pm 15.7$ & $92.7 \pm 12.4$ \\
\hline Waist circumference $(\mathrm{cm})-$ mean \pm SD & $82.6 \pm 14.7$ & $83.1 \pm 15.3$ & $81.9 \pm 13.8$ \\
\hline WHR- mean $\pm S D$ & $0.86 \pm 0.08$ & $0.85 \pm 0.08$ & $0.88 \pm 0.08$ \\
\hline WHtR- mean \pm SD & $0.51 \pm 0.09$ & $0.52 \pm 0.10$ & $0.48 \pm 0.08$ \\
\hline \multicolumn{4}{|c|}{$\mathrm{BMI}$ - body mass index; WHR - waist to hip ratio; WHtR - waist to height ratio; SD - standard } \\
\hline
\end{tabular}

Figure 1 and Figure 2 present the ROC analyses for diabetes by anthropometric measures while Table 2 presents the optimal cut-offs of anthropometric measures and their predictive ability of diabetes. 
Overall, the optimal cut-offs for BMI, WC, WHR, and WHtR were $24.8 \mathrm{~kg} \cdot \mathrm{m}^{-2}, 90.0 \mathrm{~cm}, 0.88$ and 0.54 . Overall, T2D was correctly discriminated by WC and WHtR 71\% of the time (i.e., mean AUC was 0.71 in both) compared to $68 \%$ of the time for $\mathrm{BMI}, \mathrm{p}=0.0314$ for $\mathrm{BMI}$ versus $\mathrm{WC}$ and $\mathrm{p}=0.0182$ for $\mathrm{BMI}$ versus WHtR.

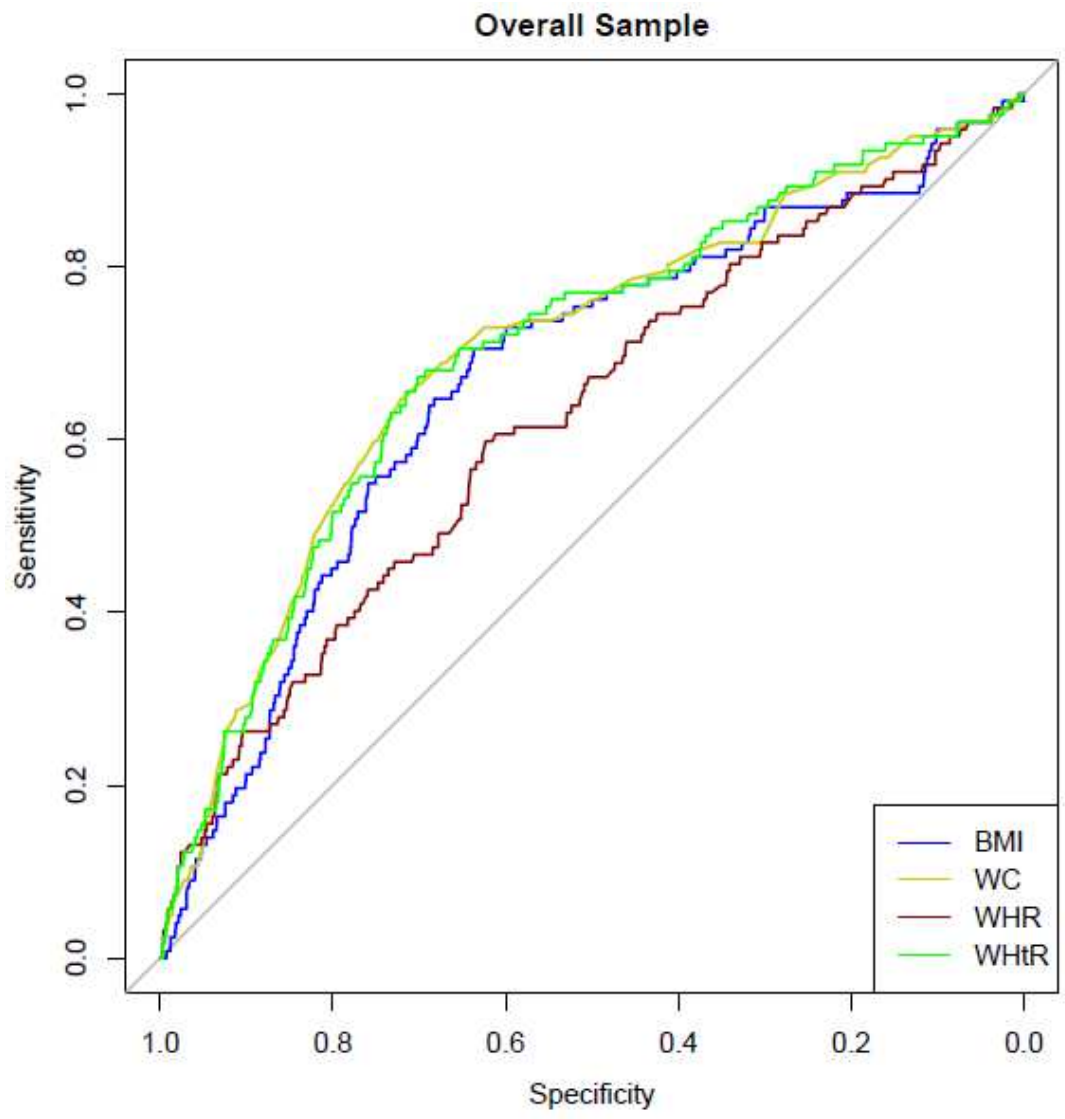

Figure 1: Receiver Operating Characteristic analyses for diabetes by anthropometric measures in the overall sample

The optimal cut-offs for BMI, WC, WHR, WHtR in women were $27.1 \mathrm{~kg} \cdot \mathrm{m}^{-2}, 87 \mathrm{~cm}, 0.85$ and $0.55 . \mathrm{In}$ women, WC and WHtR (AUC 0.71 in both) had a 3\% better discrimination for T2D than BMI (AUC 0.68) although these differences did not reach significance level, $p=0.0737$ for $B M I$ versus $W C$, and $p=0.0989$ for BMI versus WHtR. The optimal cut-offs for BMI, WC, WHR, WHtR in men were $24.8 \mathrm{~kg} \cdot \mathrm{m}^{-2}, 91 \mathrm{~cm}$, 
0.88, and 0.54. In men, WC and WHtR (AUC 0.68 in both) had a $5 \%$ better discriminative ability for T2D than BMI (AUC 0.63), $p=0.0213$ for BMI versus $W C$, and $p=0.0323$ for $B M I$ versus $W H t R$.
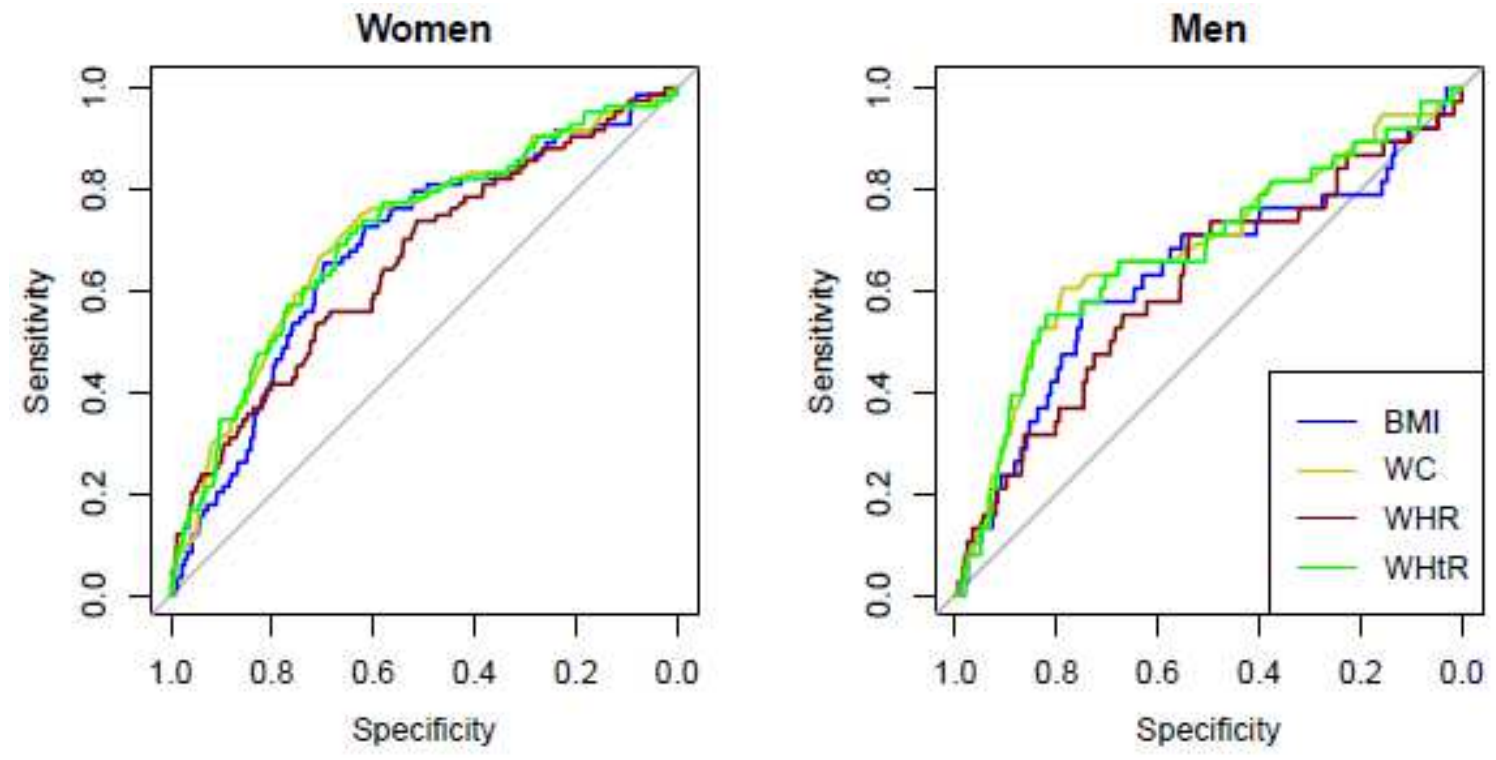

Figure 2: Receiver Operating Characteristic analyses for diabetes by anthropometric measures in women and men

Table 2: Optimal anthropometric cut-offs and their predictive ability of diabetes

\begin{tabular}{|c|c|c|c|c|c|c|c|}
\hline & $\begin{array}{l}\text { Optimal } \\
\text { cut-off }\end{array}$ & AUC (95\% Cl) & $\begin{array}{l}\text { P value for } \\
\text { difference } \\
\text { in AUC }\end{array}$ & $\begin{array}{l}\text { Sensitivity } \\
\text { (\%) }\end{array}$ & $\begin{array}{l}\text { Specificity } \\
\text { (\%) }\end{array}$ & $\begin{array}{l}\text { Positive } \\
\text { predictive } \\
\text { value (\%) }\end{array}$ & $\begin{array}{l}\text { Negative } \\
\text { predictive } \\
\text { value (\%) }\end{array}$ \\
\hline \multicolumn{8}{|c|}{ Body mass index $\left(\mathrm{kg} \cdot \mathrm{m}^{-2}\right)$} \\
\hline Overall & 24.8 & $0.68(0.62,0.73)$ & & $70(62,78)$ & $64(62,66)$ & $11(10,16)$ & $97(96,97)$ \\
\hline Women & 27.1 & $0.68(0.62,0.74)$ & & $65(54,76)$ & $70(67,72)$ & $14(12,21)$ & $96(94,97)$ \\
\hline
\end{tabular}




\begin{tabular}{|c|c|c|c|c|c|c|c|}
\hline Men & 24.8 & $0.63(0.53,0.73)$ & & $58(41,74)$ & $75(72,78)$ & $10(8,18)$ & $97(95,98)$ \\
\hline \multicolumn{8}{|c|}{ Waist circumference (cm) } \\
\hline Overall & 90.0 & $0.71(0.65,0.76)$ & 0.0314 & $65(56,73)$ & $73(71,75)$ & $13(12,18)$ & $97(96,97)$ \\
\hline Women & 87.0 & $0.71(0.65,0.77)$ & 0.0737 & $75(64,84)$ & $62(60,65)$ & $13(12,20)$ & $97(95,97)$ \\
\hline Men & 91.0 & $0.68(0.59,0.78)$ & 0.0213 & $61(43,76)$ & $79(76,82)$ & $12(10,22)$ & $98(96,98)$ \\
\hline \multicolumn{8}{|c|}{ Waist to hip ratio } \\
\hline Overall & 0.88 & $0.63(0.57,0.68)$ & 0.1332 & $60(51,69)$ & $63(61,65)$ & $9(8,13)$ & $96(95,97)$ \\
\hline Women & 0.85 & $0.66(0.60,0.72)$ & 0.5124 & $74(63,83)$ & $51(48,54)$ & $10(9,16)$ & $96(94,97)$ \\
\hline Men & 0.88 & $0.61(0.51,0.71)$ & 0.7256 & $71(54,85)$ & $54(50,57)$ & $7(6,14)$ & $98(95,98)$ \\
\hline
\end{tabular}

Waist to height ratio

\begin{tabular}{llllllll}
\hline Overall & 0.54 & $0.71(0.66,0.76)$ & 0.0182 & $67(58,75)$ & $71(69,73)$ & $13(12,18)$ & $97(96,97)$ \\
& & & & & & & \\
\hline Women & 0.55 & $0.71(0.65,0.77)$ & 0.0989 & $71(61,81)$ & $65(62,67)$ & $13(12,20)$ & $97(95,97)$ \\
\hline Men & 0.54 & $0.68(0.58,0.77)$ & 0.0323 & $55(38,71)$ & $82(79,85)$ & $13(11,23)$ & $98(95,98)$
\end{tabular}

Italicised $\mathrm{p}$ values are significant.

AUC - Area Under the Curve; $\mathrm{Cl}$ - confidence interval

Data in brackets are $95 \%$ confidence intervals

\section{Discussion}

This study aimed to determine optimal anthropometric cut-offs to predict T2D and compare their predictive ability. The optimal BMI cut-off was $27.1 \mathrm{~kg} \cdot \mathrm{m}^{-2}$ and $24.8 \mathrm{~kg} \cdot \mathrm{m}^{-2}$ in women and men, respectively. These findings were consistent with a Ghanaian study which found an overweight BMI 
of $26.2 \mathrm{~kg} \cdot \mathrm{m}^{-2}$ as the optimal cut-off in women (8) and an Ethiopian study that reported a normal weight BMI of $23.0 \mathrm{~kg} \cdot \mathrm{m}^{-2}$ as the optimal cut-off in men (12). Also, this is in agreement with increasing evidence that Africans develop T2D at a lower BMI (23) than the current obesity cut-off of $30 \mathrm{~kg} \cdot \mathrm{m}^{-2}$ (24). Further, WC and WHtR had a better discriminatory ability for T2D than BMI. This agrees with other findings from Guinea, Kenya, Cameroon, and Ethiopia which have shown that WC is a better predictor of T2D (7, 9-12). Globally, these findings are consistent with a meta-analysis that found that WC and WHtR had better discrimination for T2D than BMI (6). WC and WHtR are proxies of visceral fat which confers a higher risk of metabolic complications such as T2D compared to peripheral fat (25). This implies that these measures, rather than BMI, should be used for risk stratification in Kenya.

We found the optimal WC cut-off as $87 \mathrm{~cm}$ for women and $91 \mathrm{~cm}$ for men. These cut-offs differ from those from other SSA settings: in Ghana, the optimal cut-off was $91.7 \mathrm{~cm}$ for women and $83.4 \mathrm{~cm}$ for men (8) while in Ethiopia the optimal cut-off was $82.9 \mathrm{~cm}$ for women and $88.6 \mathrm{~cm}$ for men (12). Despite these contrasts, our findings show a similar trend to the other two studies, that is, the cut-offs for women are above the WHO cut-off for metabolic complications $(\geq 80 \mathrm{~cm})$ while the cut-offs in men are below the WHO thresholds ( $\geq 94 \mathrm{~cm}$ ) (24). A similar trend has been reported by a large analysis of data ( $n=24181$ ) from eight SSA countries which showed that men were at increased cardiometabolic risk at lower WC $(\geq 81.2 \mathrm{~cm})$ than current guidelines $(\geq 94 \mathrm{~cm})(26)$. This implies that a WC cut-off of $\geq 91 \mathrm{~cm}$ should be used for predicting T2D risk in men instead of the recommended $\geq 94 \mathrm{~cm}$. In women, the WHO recommended cut-off of $\geq 88 \mathrm{~cm}$ which corresponds to "substantially increased risk" of metabolic complications (24) should be used to predict T2D risk in Kenya.

The optimal WHtR cut-off was relatively similar for women and men -0.55 and 0.54 , respectively. This is slightly higher than what was reported in Ethiopia - 0.51 in men and 0.52 in women (12). The derived WHtR cut-offs are relatively similar to the recommended and widely used cut-off of $\geq 0.5$ in women and men which translates to a simple screening message of "keep your waist to less than half your height" (27-29). Apart from a simple public health message, the same WHtR cut-off is used for both 
men and women, and adults and children (29). Further, WHtR is easier to measure and calculate than $\mathrm{BMI}$ and a string can be used for measurement (a string measuring half someone's height should fit around their waist) making it a very cheap screening method $(27,29)$. This implies there is need to consider the use of WHtR in risk stratification and associated simple public health messaging to intervene on central obesity and prediction of T2D risk.

This study adds to the limited evidence on optimal anthropometric cut-offs and their predictive ability of T2D in Kenya and SSA. Its strengths are the use of a large nationally representative sample, and identification of optimal cut-offs, and predictive ability of all four commonly used anthropometric measures. However, just like the recommended cut-offs, the study uses cross-sectional evidence which limits causal inference of derived cut-offs on T2D. More evidence, particularly from prospective studies, is needed to confirm if the derived cut-offs are the most appropriate for T2D prediction.

In conclusion, WC and WHtR were better predictors of T2D than BMI highlighting their utility in risk stratification. The optimal cut-offs of WC $(87 \mathrm{~cm}$ for women and $91 \mathrm{~cm}$ for men) and WHtR $(0.54$ for women and men) should be used for risk stratification in Kenya.

\section{Availability of data and materials}

The Kenya STEPwise survey 2014 data can be assessed from the Kenya National Bureau of Statistics using this link: http://statistics.knbs.or.ke/nada/index.php/catalog/90

Ethics approval and consent to participate.

Not applicable

\section{Consent for publication}

Not applicable

\section{Competing interests}

The authors declare that they have no competing interests. 
Funding

Not applicable

Authors' contributions

AMM conceptualised the study, analysed and interpreted the data, and drafted the manuscript.

\section{References}

1. Pastakia SD, Pekny CR, Manyara SM, Fischer L. Diabetes in sub-Saharan Africa-from policy to practice to progress: targeting the existing gaps for future care for diabetes. Diabetes, metabolic syndrome and obesity: targets and therapy. 2017;10:247.

2. Dunkley AJ, Bodicoat DH, Greaves CJ, Russell C, Yates T, Davies MJ, et al. Diabetes Prevention in the Real World: Effectiveness of Pragmatic Lifestyle Interventions for the Prevention of Type 2 Diabetes and of the Impact of Adherence to Guideline Recommendations. A Systematic Review and Meta-analysis. 2014;37(4):922-33.

3. Bellou V, Belbasis L, Tzoulaki I, Evangelou E. Risk factors for type 2 diabetes mellitus: An exposure-wide umbrella review of meta-analyses. PloS one. 2018;13(3):e0194127.

4. Nuttall FQ. Body Mass Index: Obesity, BMI, and Health: A Critical Review. Nutrition today. 2015;50(3):117-28.

5. Sattar N, Gill JMR. Type 2 diabetes as a disease of ectopic fat? BMC Medicine. 2014;12(1):123.

6. Ashwell M, Gunn P, Gibson S. Waist-to-height ratio is a better screening tool than waist circumference and BMI for adult cardiometabolic risk factors: systematic review and meta-analysis. Obesity reviews : an official journal of the International Association for the Study of Obesity. 2012;13(3):275-86.

7. Baldé NM, Diallo I, Baldé MD, Barry IS, Kaba L, Diallo MM, et al. Diabetes and impaired fasting glucose in rural and urban populations in Futa Jallon (Guinea): prevalence and associated risk factors. Diabetes \& metabolism. 2007;33(2):114-20.

8. Frank LK, Heraclides A, Danquah I, Bedu-Addo G, Mockenhaupt FP, Schulze MB. Measures of general and central obesity and risk of type 2 diabetes in a Ghanaian population. Tropical Medicine \& International Health. 2013;18(2):141-51.

9. Haregu TN, Oti S, Egondi T, Kyobutungi C. Measurement of overweight and obesity an urban slum setting in sub-Saharan Africa: a comparison of four anthropometric indices. BMC Obesity. 2016;3(1):46.

10. Mbanya V, Kengne A, Mbanya J, Akhtar H. Body mass index, waist circumference, hip circumference, waist-hip-ratio and waist-height-ratio: Which is the better discriminator of prevalent screen-detected diabetes in a Cameroonian population? Diabetes research and clinical practice. 2015;108(1):23-30.

11. Tesfaye T, Shikur B, Shimels T, Firdu N. Prevalence and factors associated with diabetes mellitus and impaired fasting glucose level among members of federal police commission residing in Addis Ababa, Ethiopia. BMC endocrine disorders. 2016;16(1):68.

12. Woldegebriel AG, Fenta KA, Aregay AB, Aregay AD, Mamo NB, Wubayehu TW, et al. Effectiveness of Anthropometric Measurements for Identifying Diabetes and Prediabetes among Civil Servants in a Regional City of Northern Ethiopia: A Cross-Sectional Study. J Nutr Metab [Internet]. 2020 2020; 2020:[8425912 p.]. Available from:

http://europepmc.org/abstract/MED/32322417 
13. Mayige M. Derivation and validation of a simple risk score for undiagnosed diabetes for Tanzania and other African populations: Newcastle University; 2014.

14. Ntuk UE, Gill JM, Mackay DF, Sattar N, Pell JP. Ethnic-specific obesity cutoffs for diabetes risk: cross-sectional study of 490,288 UK biobank participants. Diabetes care. 2014:DC_132966.

15. Health Mo. Kenya STEPwise survey for non-communicable diseases risk factors 2015 report. 2015.

16. Suastika K, Dwipayana P, Semadi MS, Kuswardhani RT. Age is an important risk factor for type 2 diabetes mellitus and cardiovascular diseases. Glucose Tolerance. 2012:67-80.

17. Diaz-Valencia PA, Bougnères $P$, Valleron A-J. Global epidemiology of type 1 diabetes in young adults and adults: a systematic review. BMC Public Health. 2015;15(1):255.

18. WHO. Obesity: preventing and managing the global epidemic: World Health Organization; 2000.

19. WHO. Definition and diagnosis of diabetes mellitus and intermediate hyperglycaemia: report of a WHO/IDF consultation. 2006.

20. Team RC. R: A language and environment for statistical computing. Vienna, Austria; 2013.

21. López Ratón M, Rodríguez Álvarez MX, Cadarso Suárez CM, Gude Sampedro F, editors. OptimalCutpoints: an R package for selecting optimal cutpoints in diagnostic tests2014: American Statistical Association.

22. Robin X, Turck N, Hainard A, Tiberti N, Lisacek F, Sanchez J-C, et al. Package 'pROC'. 2012-0910 09: 34; 2021.

23. Kibirige D, Lumu W, Jones AG, Smeeth L, Hattersley AT, Nyirenda MJ. Understanding the manifestation of diabetes in sub Saharan Africa to inform therapeutic approaches and preventive strategies: a narrative review. Clinical Diabetes and Endocrinology. 2019;5(1):2.

24. WHO. Waist circumference and waist-hip ratio: report of a WHO expert consultation, Geneva, 8-11 December 2008. 2011.

25. Lee M-J, Wu Y, Fried SK. Adipose tissue heterogeneity: implication of depot differences in adipose tissue for obesity complications. Mol Aspects Med. 2013;34(1):1-11.

26. Ekoru K, Murphy G, Young E, Delisle H, Jerome C, Assah F, et al. Deriving an optimal threshold of waist circumference for detecting cardiometabolic risk in sub-Saharan Africa. International Journal of Obesity. 2018;42(3):487-94.

27. Ashwell M, Gibson S. A proposal for a primary screening tool: 'Keep your waist circumference to less than half your height'. BMC Medicine. 2014;12(1):207.

28. Ashwell M, Gibson S. Waist-to-height ratio as an indicator of 'early health risk': simpler and more predictive than using a 'matrix'based on BMI and waist circumference. BMJ open. 2016;6(3):e010159.

29. Ashwell M, Hsieh SD. Six reasons why the waist-to-height ratio is a rapid and effective global indicator for health risks of obesity and how its use could simplify the international public health message on obesity. International Journal of Food Sciences and Nutrition. 2005;56(5):303-7. 
Figures

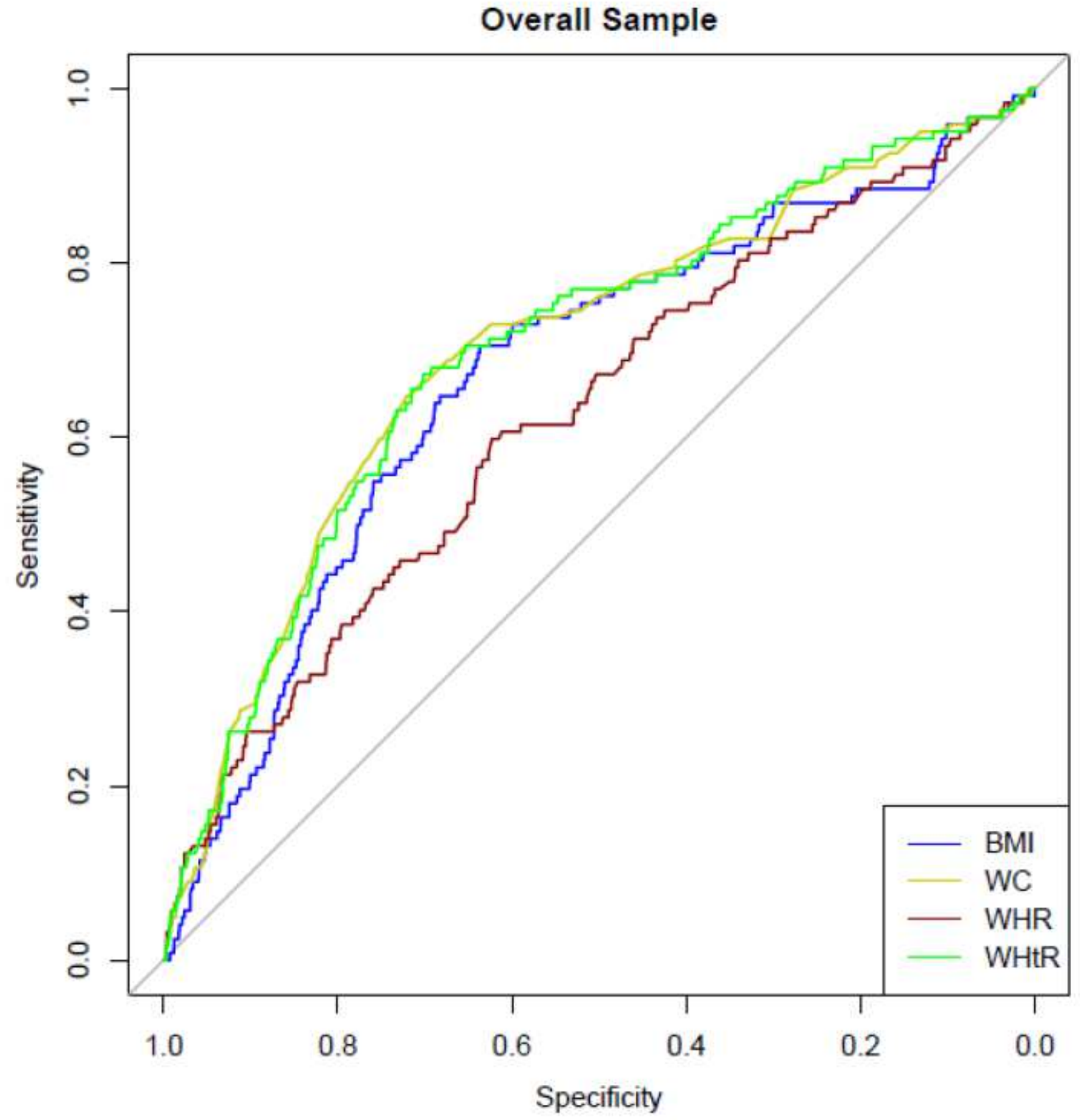

Figure 1

Receiver Operating Characteristic analyses for diabetes by anthropometric measures in the overall sample 

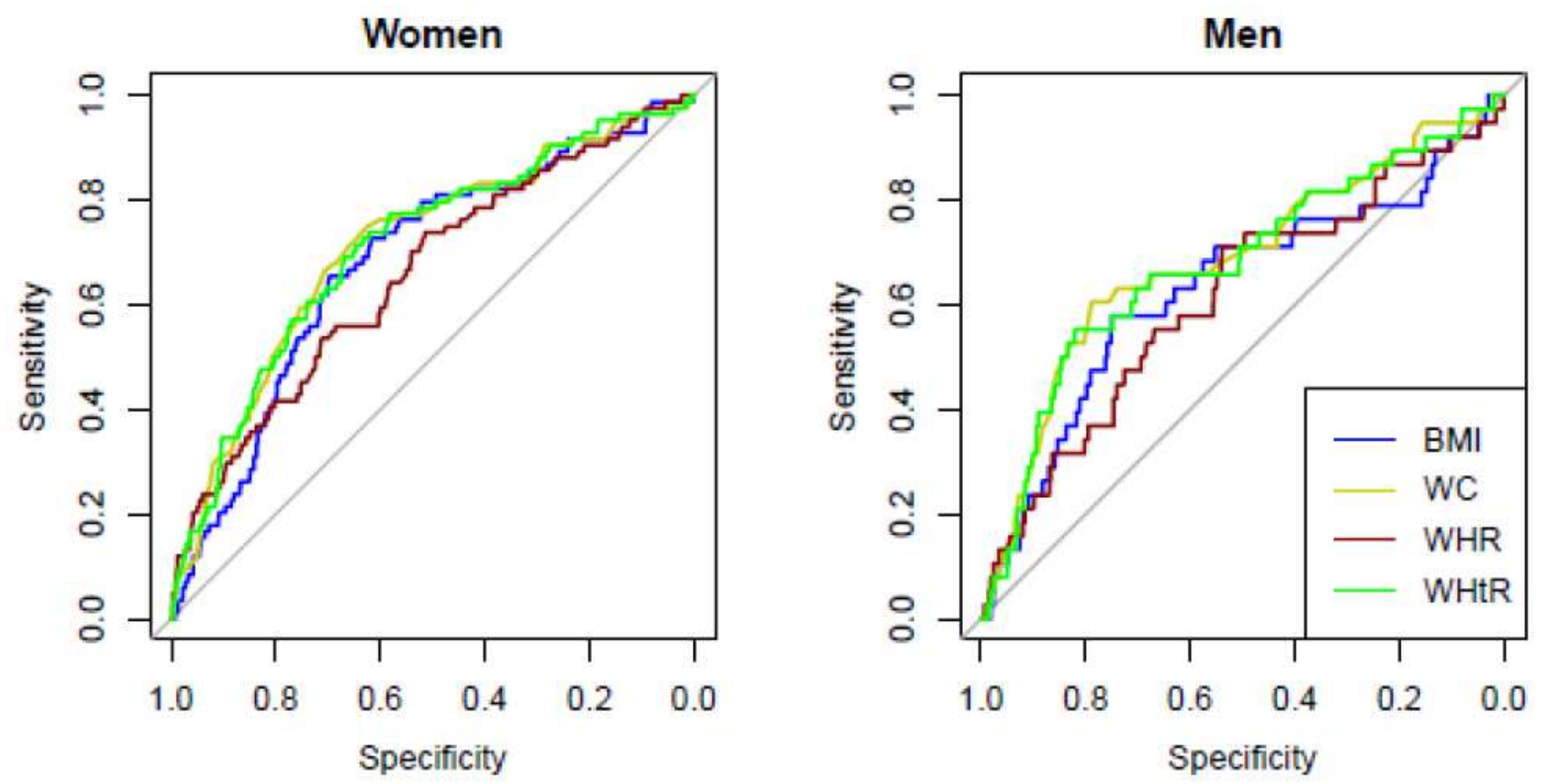

Figure 2

Receiver Operating Characteristic analyses for diabetes by anthropometric measures in women and men 